\title{
De Novo Design of an Allosteric Metalloprotein Assembly with Strained Disulfide Bonds
}

Lewis A. Churchfield, Annette Medina-Morales, Jeffrey D. Brodin, Alfredo Perez, and F. Akif Tezcan*

Department of Chemistry and Biochemistry, University of California, San Diego, La Jolla, California 92093-0356.

This file contains Supporting Tables S1-4, and Supporting Figures S1-S9.

\section{Supplementary Figures and Tables}

Table S1: Thermodynamic parameters for $\mathrm{Zn}^{2+}$ binding to disulfide-linked $\mathrm{R} 1_{4}$ tetramers.

Table S1: X-ray crystallography data collection and refinement statistics.

Table S3: Calculated strain energies of disulfide bonds in C38/C81/C96 $\mathrm{R} 1_{4}$ structures.

Table S4: Relative accessible solvent areas of disulfide bonds in $\mathrm{C} 38 / \mathrm{C} 81 / \mathrm{C} 96 \mathrm{R} 1_{4}$ structures.

Figure S1: Successive engineering of cyt $c b_{562}$ to form disulfide-linked protein oligomers.

Figure S2: Zn-induced structural rearrangements in $\mathrm{C} 81 / \mathrm{C} 96 \mathrm{R} 1$.

Figure S3: SDS-PAGE of C38/C81/C96R 1 and C38/C81/C96 M1 self-assembly reactions.

Figure S4: Fluorescence excitation scans from C38/C81/C96 $\mathrm{R} 1_{4}$-Fura-2 $\mathrm{Zn}^{2+}$ competition assay.

Figure S5: ITC thermograms of disulfide-linked $\mathrm{R} 1_{4}$ variants titrated with $\mathrm{Zn}^{2+}$.

Figure S6: Structural overlays of disulfide-linked $\mathrm{Zn}-\mathrm{R} 1_{4}$ variants.

Figure S7: Structural overlay of $\mathrm{Zn}-\mathrm{C} 38 / \mathrm{C} 81 / \mathrm{C} 96 \mathrm{R} 1_{4}$ and $\mathrm{C} 38 / \mathrm{C} 81 / \mathrm{C} 96 \mathrm{R} 1_{4}$.

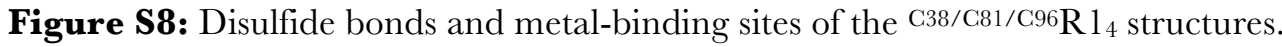

Figure S9: Surface representation of interfacial cleft in $\mathrm{C} 38 / \mathrm{C} 81 / \mathrm{C} 96 \mathrm{R} 1_{4}$.

\section{Supplementary Methods}

2.1: Protein sample preparation.

2.2: Tetramer self-assembly and purification.

2.3: Sedimentation velocity analytical ultracentrifugation.

2.4: Competitive $\mathrm{Zn}^{2+}$ titration assay.

2.5: X-ray crystallography.

2.6: Isothermal titration calorimetry.

\section{References}


Table S1. Thermodynamic parameters for $\mathrm{Zn}^{2+}$ binding to disulfide-linked $\mathrm{R} 1_{4}$ tetramers. Binding affinities were determined by $\mathrm{Zn}^{2+}$ titration in the presence of Fura-2. Errors denote fitting errors of a single measurement. Binding enthalpies were measured by ITC for the titration of $\mathrm{Zn}^{2+}$ with disulfide-linked $\mathrm{R} 1_{4}$ variants. Reported enthalpies are not corrected for buffer effects, and reported errors are the standard deviation among 3-4 replicate measurements. All measurements were carried out at $22{ }^{\circ} \mathrm{C}$ and in the presence of $20 \mathrm{mM} \mathrm{MOPS}, \mathrm{pH} 7+150 \mathrm{mM} \mathrm{NaCl}$. aData taken from reference 1 . bData taken from reference 2 .

\begin{tabular}{|c|c|c|c|}
\hline & C96 R $1_{4}$ & $\mathbf{C 8 1} / \mathbf{C} 96 \mathbf{R} 1_{4}$ & $\mathbf{C} 38 / \mathrm{C} 81 / \mathrm{C} 96 \mathbf{R} 1$ \\
\hline \multicolumn{4}{|l|}{$\begin{array}{l}\text { Binding } \\
\text { affinities }\end{array}$} \\
\hline $\mathrm{K}_{\mathrm{d} 1}(\mathrm{nM})$ & $1.3 \pm 0.3 \mathrm{a}$ & $2.6 \pm 0.3^{b}$ & $8.1 \pm 0.4$ \\
\hline $\mathrm{K}_{\mathrm{d} 2}(\mathrm{nM})$ & $0.53 \pm 0.07 \mathrm{a}$ & $25 \pm 4 \mathrm{~b}$ & $400 \pm 100$ \\
\hline $\mathrm{K}_{\mathrm{d} 3}(\mathrm{nM})$ & $33 \pm 8^{a}$ & - & - \\
\hline $\mathrm{K}_{\mathrm{d} 4}(\mathrm{nM})$ & $58 \pm 8^{\mathrm{a}}$ & - & - \\
\hline \multicolumn{4}{|l|}{$\begin{array}{c}\text { Binding } \\
\text { enthalpies }\end{array}$} \\
\hline$\Delta \mathrm{H}_{1, \mathrm{ITC}}(\mathrm{kJ} / \mathrm{mol})$ & $18 \pm 3$ & $14 \pm 4$ & $4 \pm 2$ \\
\hline$\Delta \mathrm{H}_{2, \mathrm{ITC}}(\mathrm{kJ} / \mathrm{mol})$ & $14 \pm 10$ & $33 \pm 6$ & $5 \pm 3$ \\
\hline$\Delta \mathrm{H}_{3, \mathrm{ITC}}(\mathrm{kJ} / \mathrm{mol})$ & $33 \pm 15$ & $11 \pm 10$ & $2 \pm 3$ \\
\hline$\Delta \mathrm{H}_{4, \mathrm{ITC}}(\mathrm{kJ} / \mathrm{mol})$ & $-3 \pm 4$ & $1 \pm 2$ & $-1 \pm 2$ \\
\hline
\end{tabular}


Table S2. X-ray crystallography data collection and refinement statistics. Values in parentheses denote statistics for the highest resolution shell.

\begin{tabular}{|c|c|c|}
\hline & $\mathrm{C} 38 / \mathrm{C} 81 / \mathrm{C} 96 \mathrm{R} 1_{4}$ & $\mathrm{Zn}-\mathrm{C} 38 / \mathrm{C81} / \mathrm{C} 96 \mathbf{R 1}_{4}$ \\
\hline \multicolumn{3}{|l|}{ Data collection } \\
\hline Space group & $P 2_{1} 2_{1} 2_{1}$ & $P 2_{1}$ \\
\hline \multicolumn{3}{|l|}{ Cell dimensions } \\
\hline$a, b, c(\AA)$ & $62.59,77.53,88.06$ & $48.06,62.53,72.44$ \\
\hline$a, \beta, \gamma\left(^{\circ}\right)$ & $90.00,90.00,90.00$ & $90.00,99.01,99.00$ \\
\hline Resolution $(\AA)$ & $38.77-2.40$ & $37.81-2.10$ \\
\hline$R_{\text {sym }}$ or $R_{\text {merge }}(\%)$ & $6.7(23.0)$ & $4.9(46.3)$ \\
\hline$I / \sigma$ & $14.9(5.7)$ & $15.0(3.0)$ \\
\hline$C C_{1 / 2}(\%)$ & $99.9(96.8)$ & $99.9(79.6)$ \\
\hline Completeness ( $\%)$ & $99.8(99.6)$ & $99.5(99.3)$ \\
\hline Redundancy & 6.9 & 3.7 \\
\hline \multicolumn{3}{|l|}{ Refinement } \\
\hline Resolution $(\AA)$ & 2.40 & 2.10 \\
\hline No. unique reflections & 17325 & 24815 \\
\hline$R_{\text {work }} / R_{\text {free }}(\%)$ & $22.5 / 26.5$ & $21.4 / 25.0$ \\
\hline \multicolumn{3}{|l|}{ No. atoms } \\
\hline Protein & 3224 & 3264 \\
\hline Ligand/ion & 172 & 195 \\
\hline Water & 64 & 73 \\
\hline \multicolumn{3}{|l|}{$B$-factors } \\
\hline Protein & 56.54 & 47.19 \\
\hline Ligand/ion & 54.31 & 43.45 \\
\hline Water & 47.83 & 39.94 \\
\hline \multicolumn{3}{|l|}{ R.m.s. deviations } \\
\hline Bond lengths $(\AA)$ & 0.008 & 0.018 \\
\hline Bond angles $\left({ }^{\circ}\right)$ & 1.30 & 1.57 \\
\hline
\end{tabular}


Table S3. Calculated strain energies of disulfide bonds in the available C83/C81/C96 $\mathrm{R} 1_{4}$ structures. Reported energies are averaged over disulfide pairs within each structure, with the exception of the single C38-C38 disulfide in apoC83/C81/C96 R $1_{4}$. Strain energies are calculated previously described by Katz and Kossiakoff. ${ }^{3}$

\begin{tabular}{|c|c|c|}
\hline Disulfide site & Average strai & $\begin{array}{c}\text { rgy }(\mathbf{k J} / \mathrm{mol}) \\
\mathrm{Zn}- \\
\text { C38/C81/C96R1 }\end{array}$ \\
\hline C38-C38 & 25 & 19 \\
\hline C81-C81 & 23 & 13 \\
\hline C96-C96 & 17 & 6 \\
\hline
\end{tabular}


Table S4. Relative accessible surface areas of cysteine residues in the available C38/C81/C96 R $1_{4}$ structures. Reported values are averaged over disulfide pairs within each structure, with the exception of the single C38-C38 disulfide in apoC83/C81/C96 R1 $1_{4}$. Values were calculated using the ASAView server (http://www.abren.net/asaview/). ${ }^{4}$

\section{Relative accessible surface areas}

\begin{tabular}{|c|c|c|}
\hline Disulfide site & C38/C81/C96R1 $1_{4}$ & $\begin{array}{c}\mathrm{Zn}- \\
\mathrm{C} 38 / \mathrm{C} 81 / \mathrm{C} 96 \mathbf{R 1}_{4}\end{array}$ \\
\hline C38-C38 & 0.08 & 0.10 \\
\hline C81-C81 & 0.21 & 0.29 \\
\hline C96-C96 & 0.14 & 0.21 \\
\hline
\end{tabular}




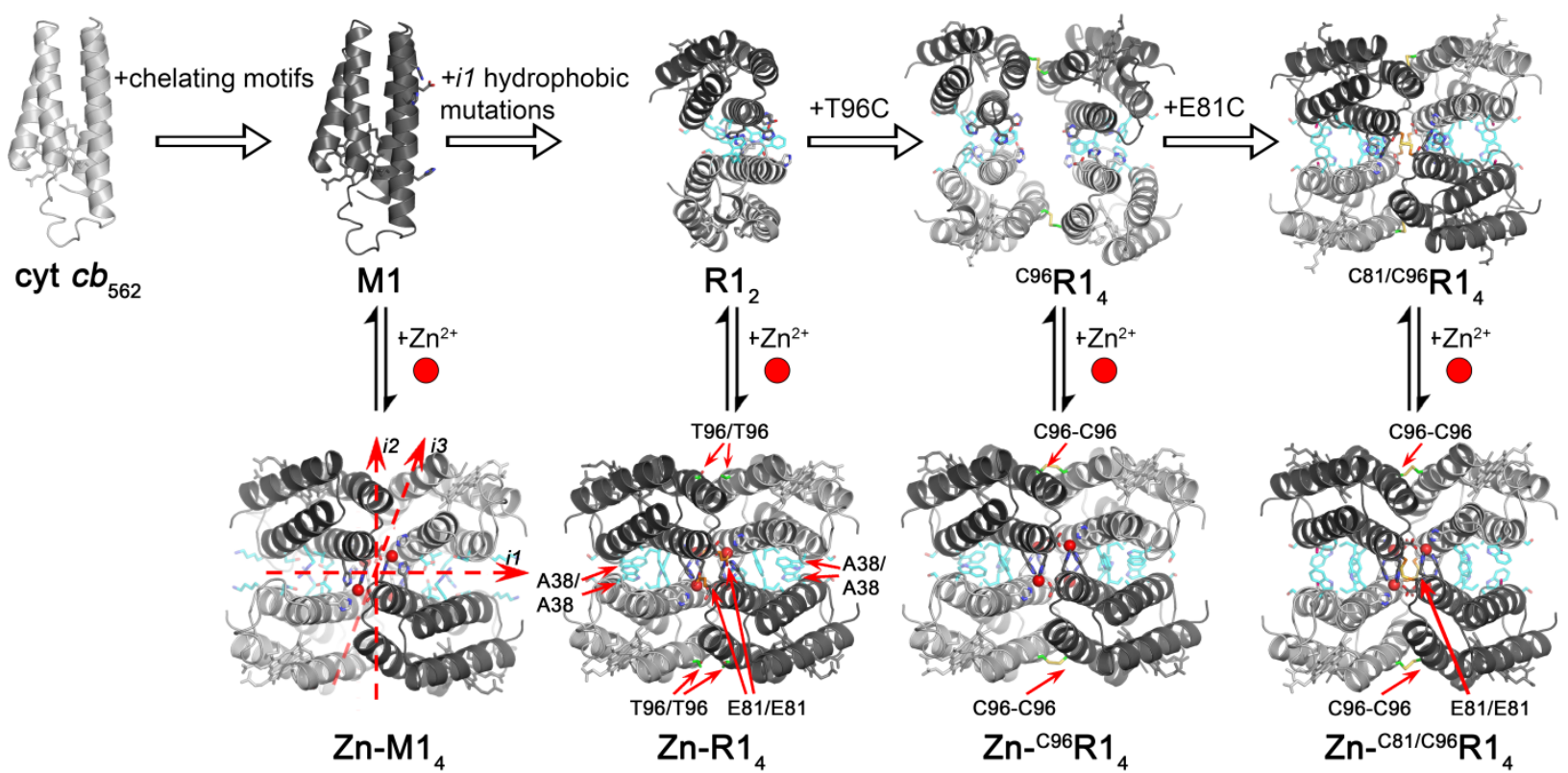

Figure S1. Successive engineering of cyt $c b_{562}$ to form disulfide-linked oligomeric architectures. Using Metal Templated Interface Redesign (MeTIR), metal chelating motifs (shown as sticks) were installed on the surface of monomeric cyt $c b_{562}$

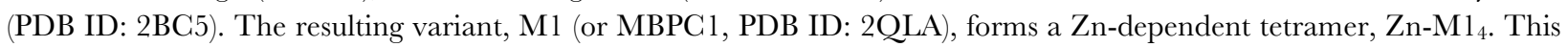
tetrameric scaffold contains three $C_{2}$ symmetric interfaces, $i 1$, $i 2$, and $i 3$. The scaffold was further engineered to include favorable protein-protein contacts at interface $i 1$ through the installation of hydrophobic patches (cyan). The second-

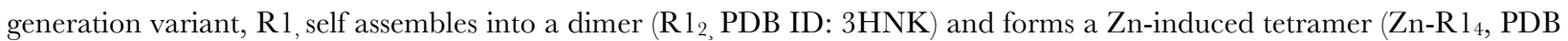
ID: $3 \mathrm{HNI}$ ) that is topologically identical to the parent variant. Within the tetramer are symmetry-related residues, A38/A38, E81/E81, and T96/T96, that are in close proximity. Previous work has shown that Zn-mediated R1 assembly can template C96-C96 (green sticks) disulfide bond formation to afford a tetrameric species that is maintained in the absence of metal (C96 R1 1 , PDB IDs: 3IQ5 and 3IQ6). Additionally, in the case of C81/C96 R1 $1_{4}, \mathrm{Zn}$-mediated R1 assembly can template the formation of C96-C96 and C81-C81 (orange sticks) disulfide bonds simultaneously (PDB IDs: 4JE9 and $4 \mathrm{JEA})$. 

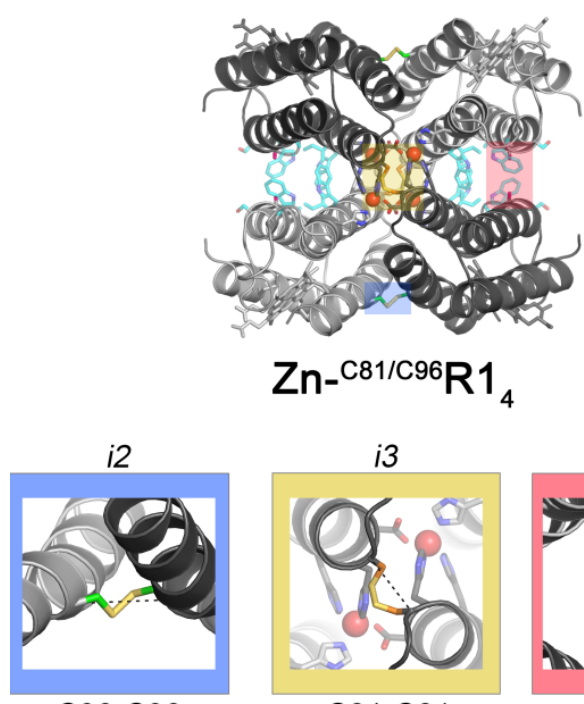

C96-C96

(6.6 $\AA)$

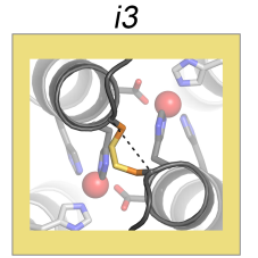

C81-C81

(5.1 A)
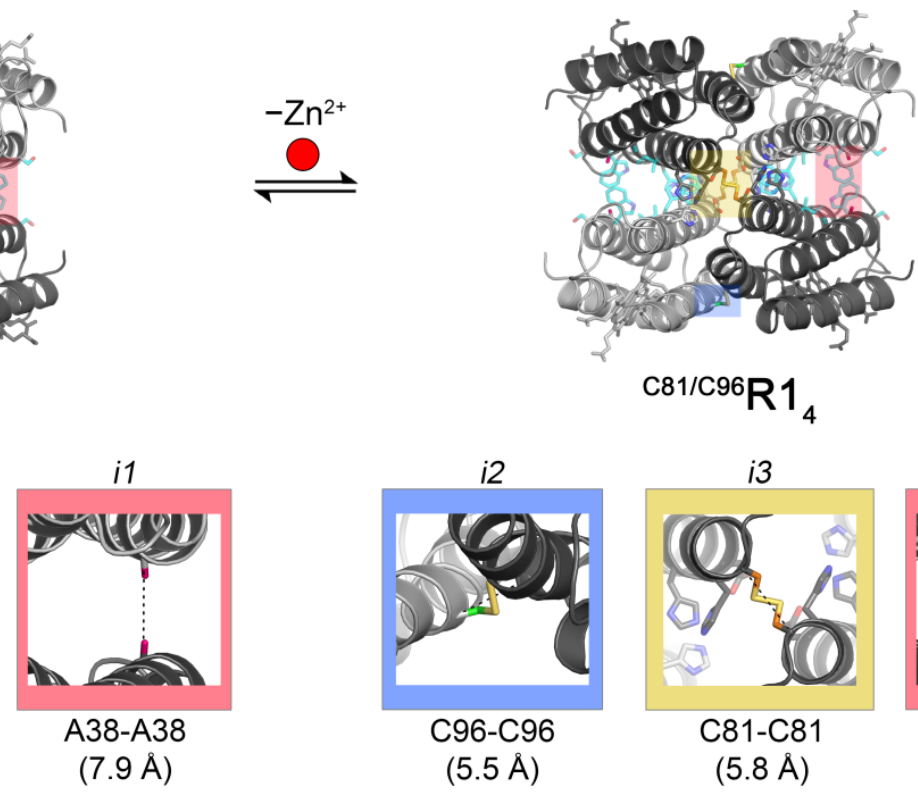

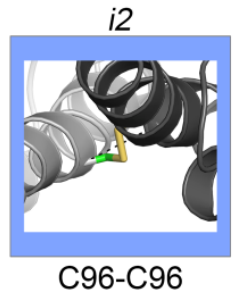

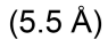

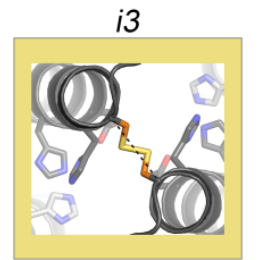

C81-C81

(5.8 A)

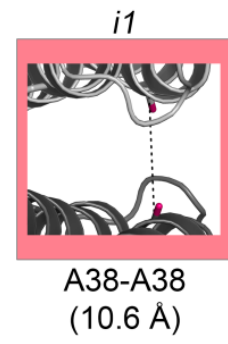

Figure S2. Structural rearrangements upon $\mathrm{Zn}^{2+}$ removal from $\mathrm{Zn}-\mathrm{C} 81 / \mathrm{C} 96 \mathrm{R} 1_{4}$. The disulfide crosslinks across interfaces $i 2$ and $i 3$ (C96-C96 and C81-C81, respectively), undergo conformational changes in a hinge-like fashion. The accompanying structural rearrangements increase the separation of the symmetry-related A38-A38 residues from $7.9 \AA$ to $10.6 \AA$. Dashed lines and values in parentheses denote the average a-carbon separations of the indicated residues in the $\mathrm{Zn}$ - and apoC38/C81/C96 $\mathrm{R}_{4}$ structures. 


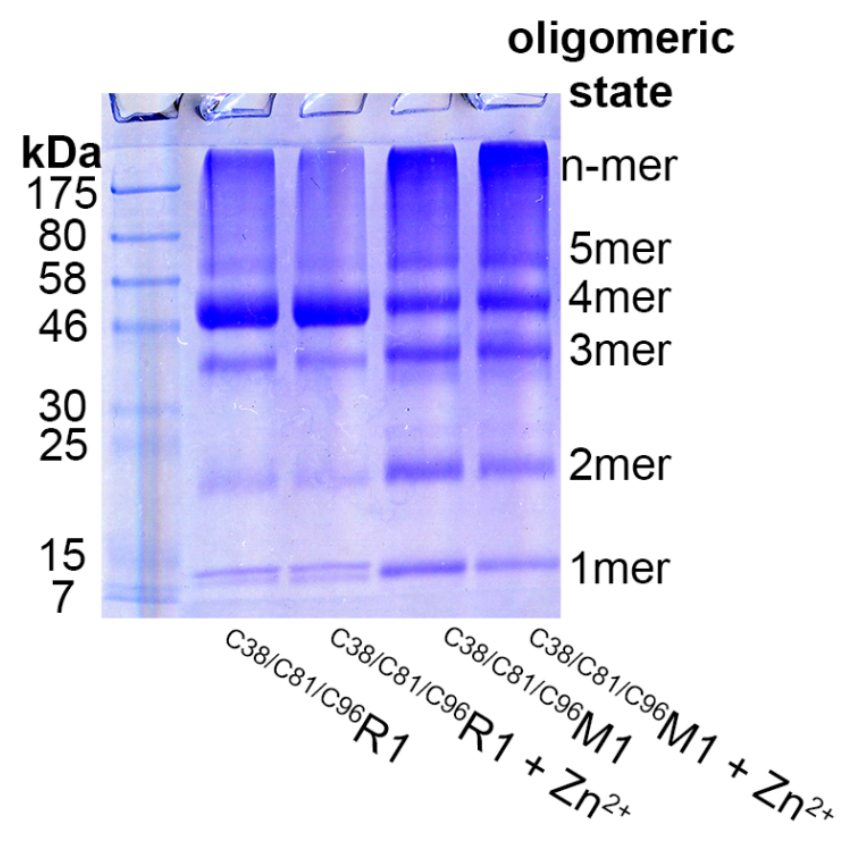

Figure S3. SDS-PAGE gel of the products of C38/C81/C96R 1 and $\mathrm{C} 38 / \mathrm{C} 81 / \mathrm{C} 96 \mathrm{M} 1$ self-assembly reactions in the presence or absence of $\mathrm{Zn}^{2+}$. The $\mathrm{C} 38 / \mathrm{C} 81 / \mathrm{C} 96 \mathrm{M} 1$ variant lacks the hydrophobic mutations engineered to stabilize the $i 1$ interfaces in C38/C81/C96 R1. The gel was run in the absence of any reductants to keep disulfide bonds intact. Self-assembly conditions are described in Section 2.2 of the Supplementary Methods. 


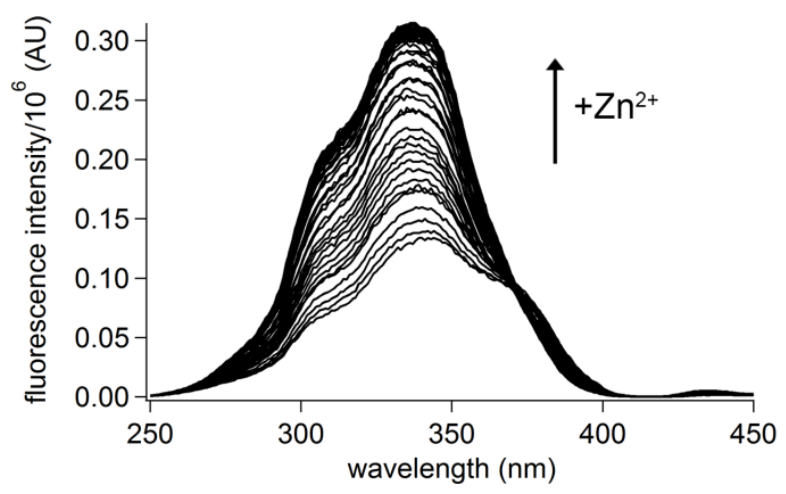

Figure S4. Competitive $\mathrm{Zn}^{2+}$ binding titration of $\mathrm{C} 38 / \mathrm{C} 81 / \mathrm{C} 96 \mathrm{R} 1_{4}$ in the presence of Fura-2. Zn competition was monitored by excitation scans at a fixed emission wavelength of $510 \mathrm{~nm}$. The corresponding changes in the intensity at $335 \mathrm{~nm}$ (shown above) were used to generate the $\mathrm{Zn}$ binding isotherms shown in Figure 3. 

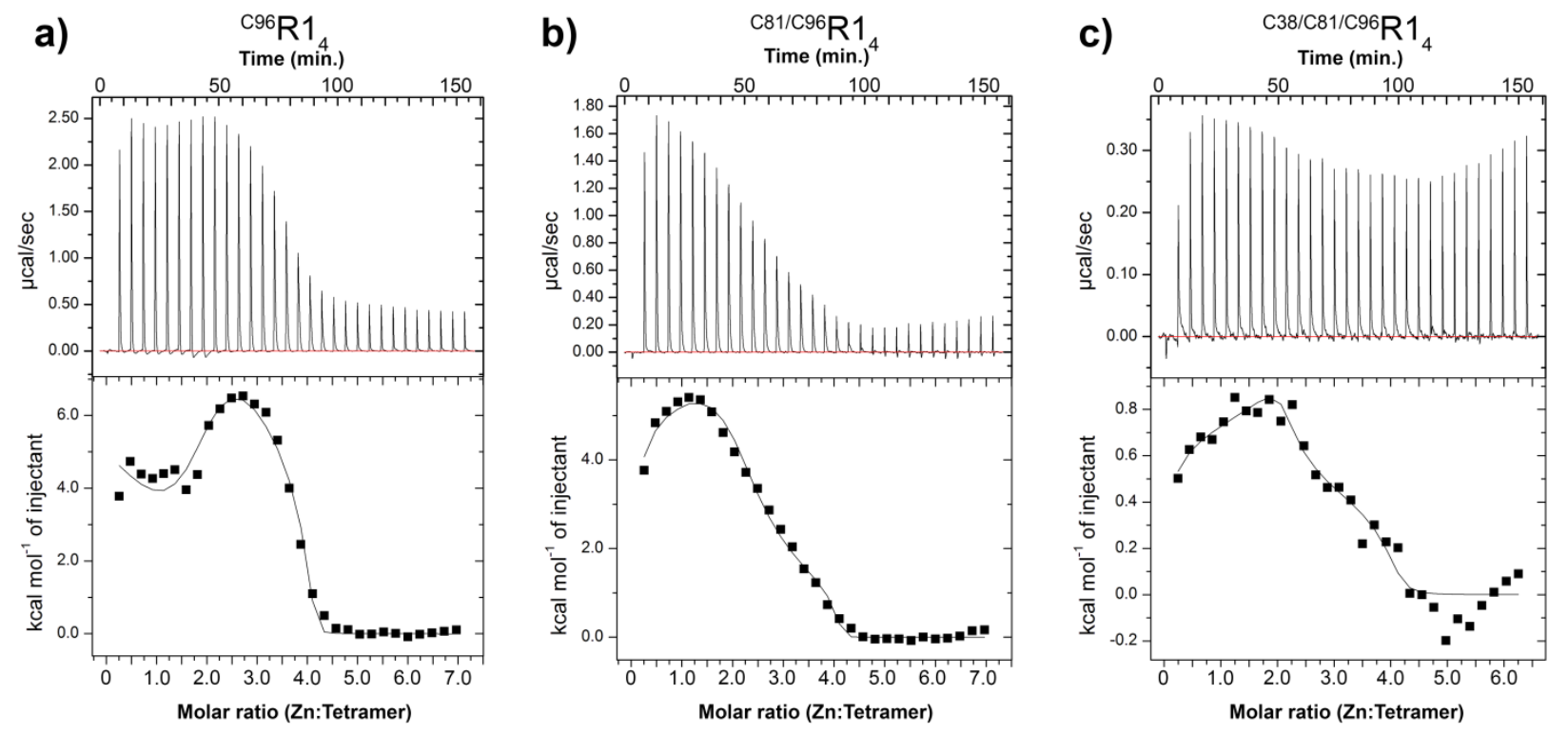

Figure S5. Representative baseline-corrected and integrated ITC thermograms for disulfide-linked $\mathrm{R} 1_{4}$ variants titrated with $\mathrm{ZnCl}_{2}$. ITG titrations and data fitting were carried out as described in Section 2.6 of the Supplementary Methods. 
a)

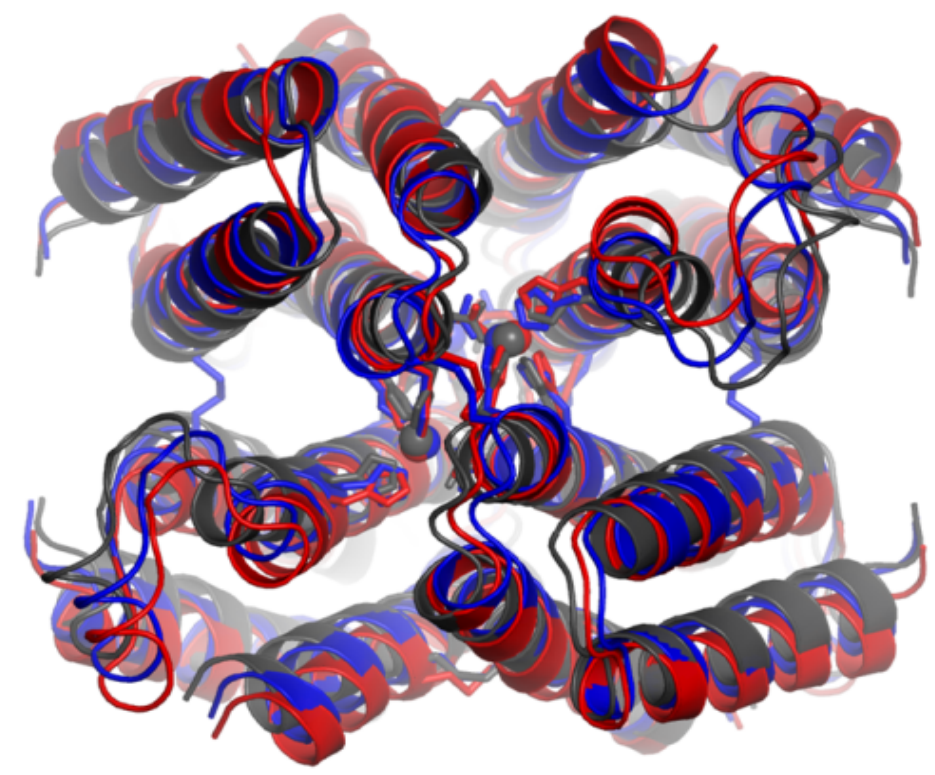

b)

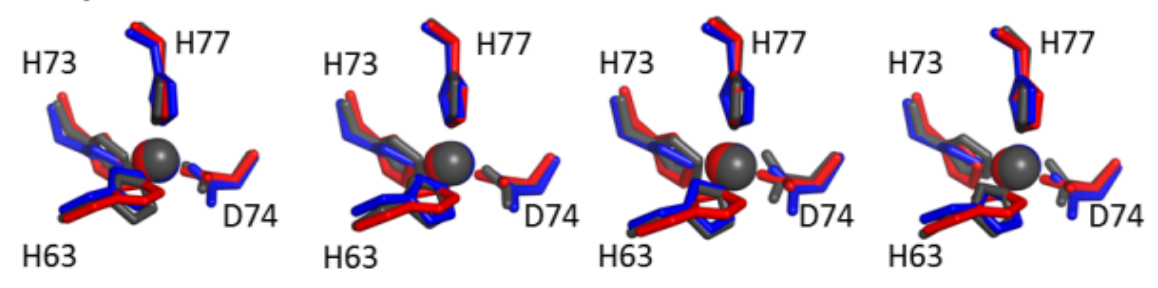

Figure S6. (a) Structural overlay of Zn-C96R $1_{4}$ (black), Zn-C81/C96R $1_{4}$ (red), and Zn-C38/C81/C96R $1_{4}$ (blue) aligned over all acarbon atoms. (b) Individual $\mathrm{Zn}^{2+}$ sites within each structure aligned to the ligand atoms only. 

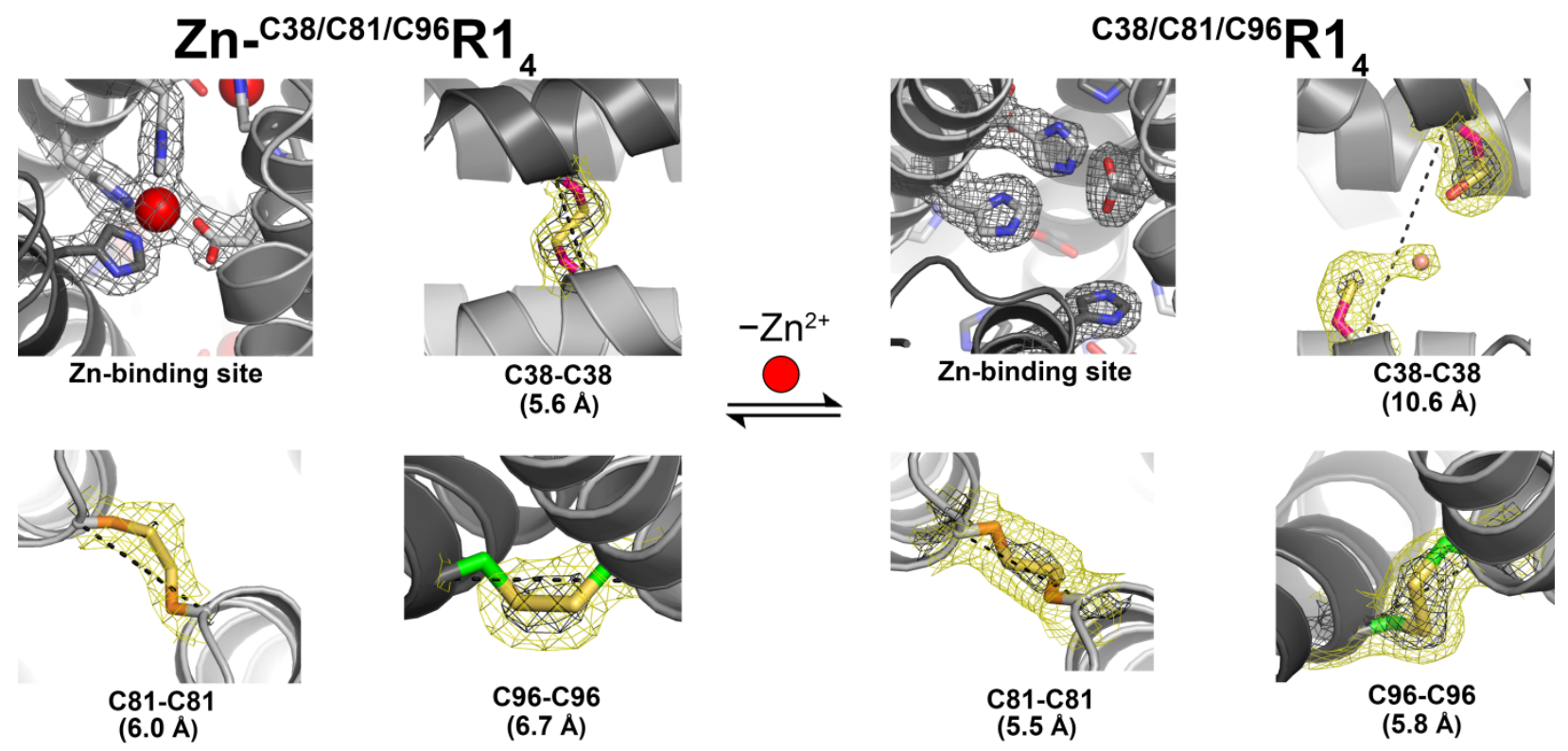

Figure S7. Close-up views of the $\mathrm{Zn}^{2+}$ coordination sites and disulfide bonds in $\mathrm{Zn}$-C38/C81/C96 $\mathrm{R} 1_{4}$ and $\mathrm{C} 38 / \mathrm{C} 81 / \mathrm{C} 96 \mathrm{R} 1_{4}$ structures. $2 F_{\mathrm{o}}-F_{\mathrm{c}}$ electron density maps are contoured at $1 \sigma$ (yellow) and $2.5 \sigma$ (black). Dashed lines and values in parentheses denote the a-carbon separation between the indicated residue pairs. 


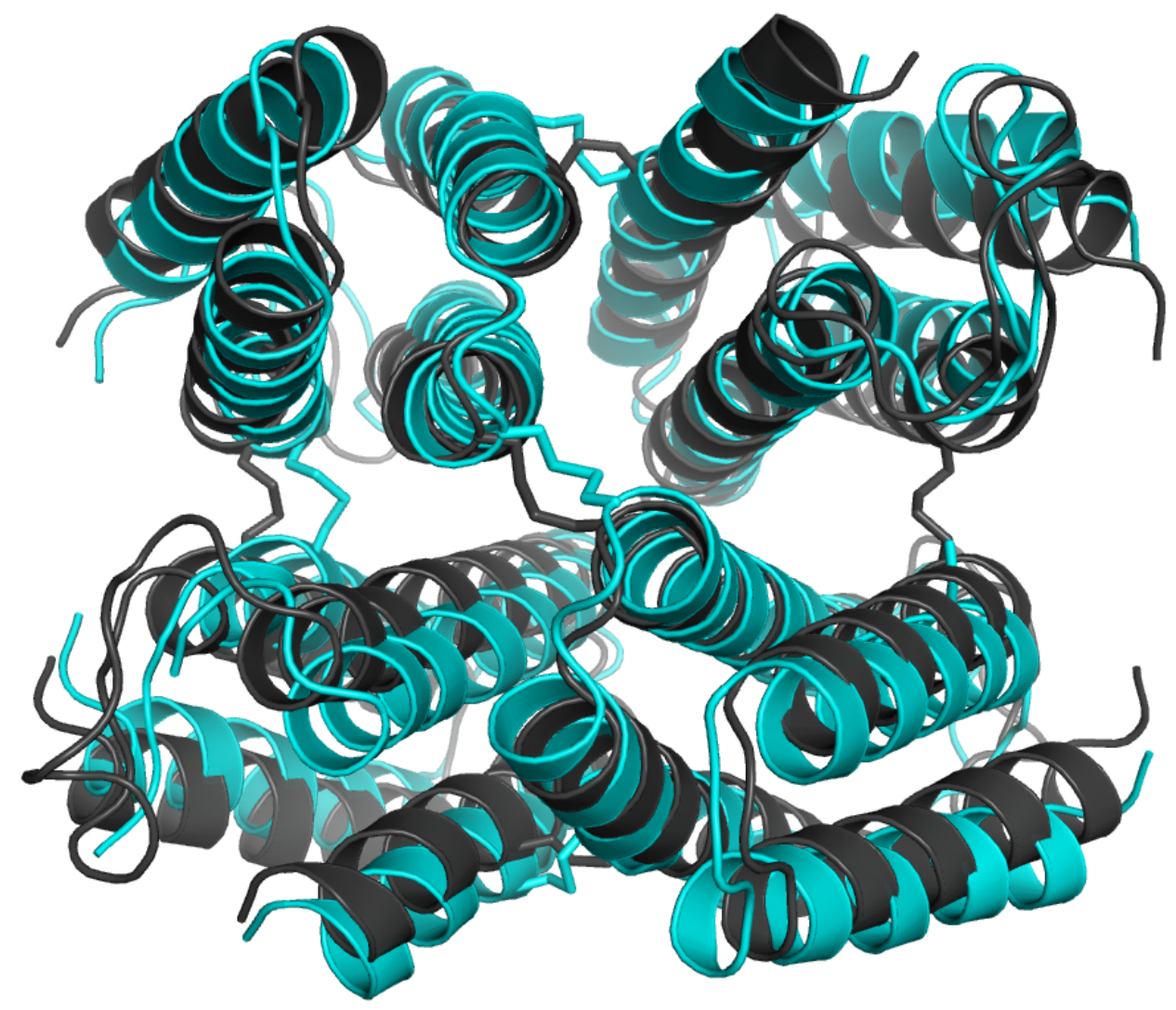

Figure S8. Structural overlay of Zn-C38/C81/C96 $\mathrm{R} 1_{4}$ (black) and C38/C81/C96 $\mathrm{R} 1_{4}$ (cyan) assemblies aligned over all a-carbon atoms (RMSD $=2.55 \AA$ ). Disulfide bonds and the broken C38-C38 disulfide are shown as sticks. 


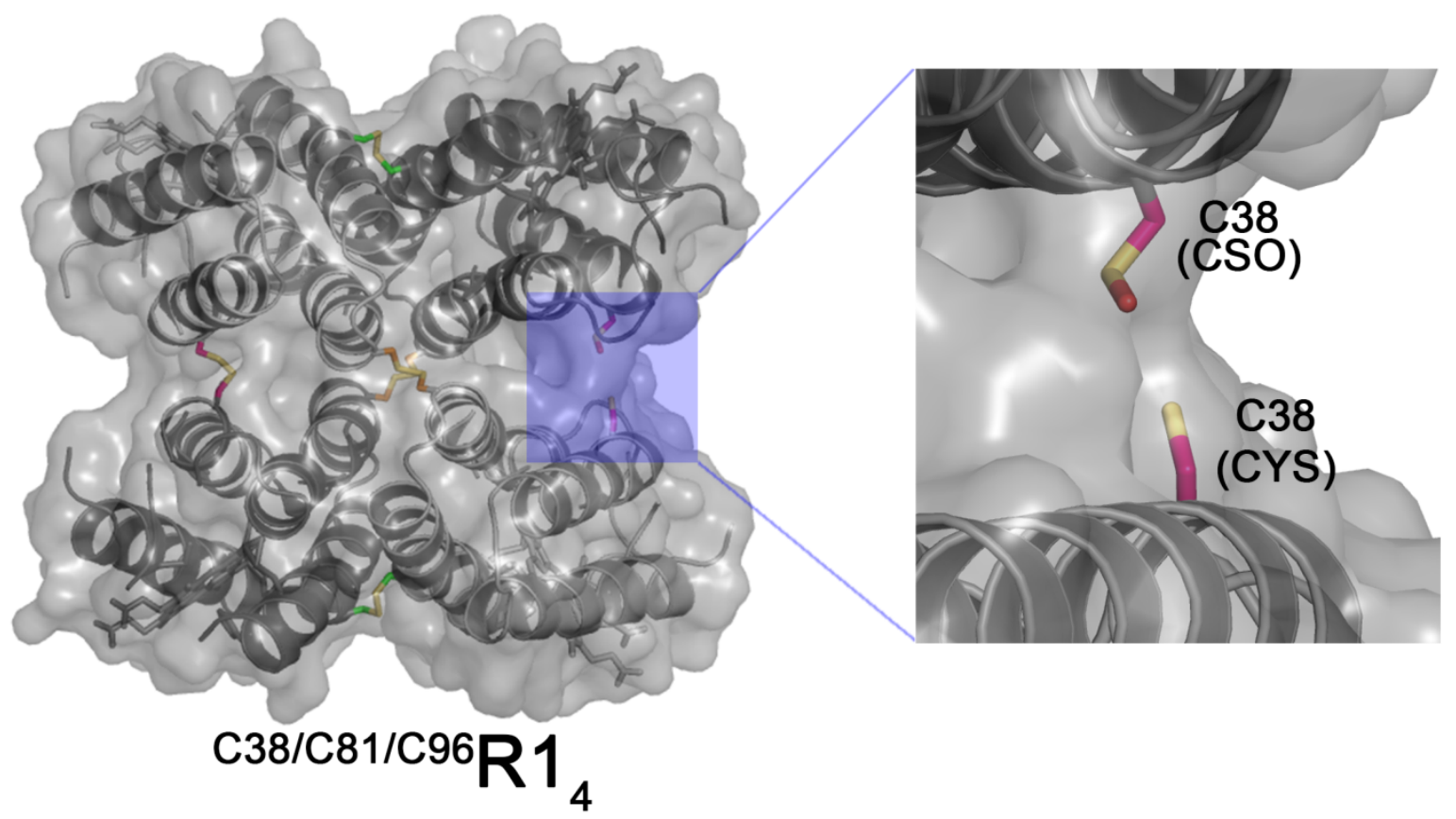

Figure S9. Surface representation of the $\mathrm{C} 38 / \mathrm{C} 81 / \mathrm{C} 96 \mathrm{R} 1_{4}$ crystal structure contoured at $1.4 \AA$. The close-up view shows the broken C38-C38 disulfide bond, which is located within an interfacial cleft of the tetramer. Disulfide bonds and the broken C38-C38 disulfide are shown as sticks. 


\section{Supplementary Methods}

2.1 Protein sample preparation. All constructs used were housed in a pet20b vector (Novagen), and coding sequences included the $\mathrm{N}$-terminal periplasmic localization sequence of $R$. palustris cytochrome $\mathrm{C}_{556 .} .^{5}$ The A38C and L38C mutations were introduced into vectors (Novagen) harboring the genes encoding $\mathrm{C} 81 / \mathrm{C} 96 \mathrm{R} 1$ and $\mathrm{C} 81 / \mathrm{C} 96 \mathrm{M} 1$, respectively, by site-directed mutagenesis using oligonucleotide primers obtained from Integrated DNA Technologies. The primer pair 5'-cgctccacgcatcgcacgctgcggccgc3' and 5'-ggcggccgcagcgtgcgatgcgtggagcg-3' was used with the pET20b/C81/C96R1 template to yield the gene encoding C38/C81/C96R1, and the primer pair 5'-gcgcgccgcagcgtgcgatgcgtggagcg-3' and 5'cgctccacgcatcgcacgctgcggcgcgc-3' was used with the pET20b/C81/C96M1 template to yield the gene encoding C38/C81/C96M1. DNA amplification was carried out using PfuTurbo DNA Polymerase (Agilent Technologies). The amplified DNA was transformed into XL-1 Blue competent E. coli cells (Agilent Technologies), and the cells were grown at $37^{\circ} \mathrm{C}$ on lysogeny broth (LB) agar plates containing $60 \mu \mathrm{g} / \mathrm{mL}$ ampicillin. Plasmids were purified with the QIAprep Spin Miniprep Kit (QIAGEN), verified by sequencing (Retrogen), and then transformed into BL21(DE3) E. coli cells (New England Biolabs) housing the cytochrome c maturation (ccm) plasmid cassette. 6 The cells were grown at $37^{\circ} \mathrm{C}$ on LB agar plates containing $34 \mu \mathrm{g} / \mathrm{mL}$ chloramphenicol and $60 \mu \mathrm{g} / \mathrm{mL}$ ampicillin. Single colonies were used to inoculate 5 $\mathrm{mL}$ of liquid LB medium containing chloramphenicol and ampicillin. Cultures were shaken at $37{ }^{\circ} \mathrm{C}$ until visibly turbid (typically about $8 \mathrm{~h}$, or to an $\mathrm{OD}_{600}>0.6$ ) at which time $50 \mu \mathrm{L}$ of inoculum was transferred to $1 \mathrm{~L}$ of LB medium, typically to 15 cultures in parallel, and shaken for $16-20 \mathrm{~h}$ at $37^{\circ} \mathrm{C}$ with protein expression occurring by auto-induction. Cells were harvested by centrifugation $\left(4,000 \mathrm{rpm}, 4{ }^{\circ} \mathrm{C}, 10 \mathrm{~min}\right)$, resuspended in $100 \mathrm{~mL}$ of $5 \mathrm{mM}$ sodium acetate $(\mathrm{pH} \mathrm{5)}$, frozen, thawed, and sonicated for $12 \mathrm{~min}$ in pulses of $30 \mathrm{~s}$ on and $60 \mathrm{~s}$ off in the presence of lysozyme and excess DTT while on ice. The lysate was titrated with sodium hydroxide to $\mathrm{pH}>10$ and acetic acid to $\mathrm{pH} 5$, and cleared by centrifugation (10,000 $\left.\mathrm{rpm}, 4^{\circ} \mathrm{C}, 10 \mathrm{~min}\right)$. The red cleared lysate was decanted and diluted to $2 \mathrm{~L}$ in $5 \mathrm{mM}$ sodium acetate (pH 5) containing $2 \mathrm{mM}$ DTT, and was manually applied to a CM Sepharose column (GE Healthcare). The sample was washed with $5 \mathrm{mM}$ sodium acetate containing $2 \mathrm{mM}$ DTT (pH 5), and eluted in a 0-1 M gradient of $\mathrm{NaCl}$. The clear red eluate was concentrated and buffer-exchanged into $10 \mathrm{mM}$ sodium phosphate $(\mathrm{pH}$ 8) containing $2 \mathrm{mM}$ DTT using a Diaflow concentrator (Amicon) fitted with a 3-kDa cutoff membrane. The sample was loaded onto a DuoFlow fast protein liquid chromatography station fitted with a Macroprep High Q-cartridge column (BioRad) with $10 \mathrm{mM}$ sodium phosphate (pH 8) running buffer containing $2 \mathrm{mM}$ DTT, and eluted using a $0-0.5 \mathrm{M} \mathrm{NaCl}$ gradient. Fractions with Reinheitzahl values $\left(\mathrm{A}_{421} / \mathrm{A}_{280}\right)$ above 3 were combined and concentrated, and excess EDTA and DTT (>10 molar equivalents) was added to the protein samples to remove any bound metal ions and prevent disulfide formation. These stock solutions were then flash frozen in liquid nitrogen for storage at $-80{ }^{\circ} \mathrm{C}$.

2.2 Tetramer self-assembly and purification. Concentrated stock solutions of C38/C81/C96R 1 (or C38/C81/C96 M1) were thawed, reduced by the addition of excess DTT, transferred to glass vials sealed with rubber septa, cycled under vacuum and argon atmosphere, and transferred to a glove box (Coy Lab) under an anaerobic $\left(<10 \mathrm{ppm} \mathrm{O}_{2}\right)$ atmosphere of argon with $10 \%$ hydrogen. Here, the samples were exchanged into an assembly buffer solution (50 mM Tris, $\mathrm{pH} \mathrm{7}$, and $150 \mathrm{mM} \mathrm{NaCl}$ ) using Econo-Pac 10DG pre-packed columns (BioRad). Protein concentration was determined spectrophotometrically $\left(\varepsilon_{421}\right.$, red $\left.=162,000 \mathrm{M}^{-1} \mathrm{~cm}^{-1} ; \varepsilon_{421, \text { ox }}=148,000 \mathrm{M}^{-1} \mathrm{~cm}^{-1}\right), 5$ and samples were diluted to a final concentration of $50 \mu \mathrm{M}$ in assembly buffer supplemented with $75 \mu \mathrm{M} \mathrm{ZnCl}$. Samples were incubated overnight under ambient atmosphere at $37^{\circ} \mathrm{C}$ with shaking. Self-assembly reactions were analyzed by SDS-PAGE in the 
absence of added reductant to keep disulfide bonds intact. The crude self-assembly reaction mixture was applied to a preparative scale Superdex 75 gel filtration column (GE Healthcare) equilibrated in assembly buffer. Purities of the tetramer-containing fractions were assessed by non-reducing SDS-PAGE. The purest fractions were combined, concentrated, and treated with $>10$-fold excess EDTA to remove bound metal, and applied to an Econo-Pac 10DG prepacked column equilibrated in $20 \mathrm{mM}$ MOPS (pH 7) and $150 \mathrm{mM} \mathrm{NaCl}$. The resulting stock solutions of $\mathrm{Zn}$-free tetramer were flash frozen in liquid nitrogen, and stored at $-80^{\circ} \mathrm{C}$.

2.3 Sedimentation velocity analytical ultracentrifugation. Solutions of $1.25 \mu \mathrm{M}$ tetramer (C38/C81/C96 $\mathrm{R}_{4}$ ) in $20 \mathrm{mM}$ MOPS (pH 7) and $150 \mathrm{mM} \mathrm{NaCl}$ were treated with either $5 \mu \mathrm{M} \mathrm{ZnCl}_{2}$ or 1 mM EDTA to prepare metallated or apo samples. Sedimentation velocity measurements were made on a XL-1 Analytical Ultracentrifuge (Beckman-Coulter) equipped with an An-60 Ti rotor at 41,000 rpm for 400 scans at $25^{\circ} \mathrm{C}$, and monitored at $415 \mathrm{~nm}$. The endpoint of sedimentation was determined using the match function in HeteroAnalysis (http://biotech.uconn.edu/auf/). Scans were processed in Sedfit ${ }^{7}$ using buffer viscosity $(0.01002$ poise), density $(1.007 \mathrm{~g} / \mathrm{mL})$ and partial specific volume $(0.7316 \mathrm{ml} / \mathrm{g})$ parameters calculated by SEDNTERP (http://sednterp.unh.edu/). The final $\mathrm{c}(\mathrm{S})$ distributions are reported at a confidence level of 0.95 .

2.4 Competitive $\mathbf{Z n}^{2+}$ titration assay. The concentration of a light-protected stock solution of Fura-2 (Invitrogen) was determined spectrophotometrically $\left(\varepsilon_{362}=27,000 \mathrm{M}^{-1} \mathrm{~cm}^{-1}\right) .{ }^{8}$ Samples of C38/C81/C96 $\mathrm{R} 1_{4}$ and Fura-2 were prepared at a final concentration of $7.5 \mu \mathrm{M}$ in a buffered solution of $20 \mathrm{mM}$ MOPS $(\mathrm{pH}$ 7) and $150 \mathrm{mM} \mathrm{NaCl}$ treated with Chelex 100 resin (BioRad). The sample was titrated with a $\mathrm{ZnCl}_{2}$ solution while thermostatted at $22{ }^{\circ} \mathrm{C}$, and fluorescence measurements were made after 5-min equilibration periods. Fura-2 fluorescence emission at $510 \mathrm{~nm}$ was monitored to obtain an excitation scan over 250-450 nm on a Horiba Fluorolog 2 fluorimeter (Figure S4). Binding isotherms were generated from the changes in emission intensity as a function of $\mathrm{Zn}^{2+}$ concentration, and were fit using Dynafit. ${ }^{9}$ Measured dissociation constants are reported in Table $\mathbf{S 1}$, and total $\Delta \mathrm{G}_{\mathrm{Zn}}$ in Table $\mathbf{1}$.

2.5 X-ray crystallography and structural analysis. For crystallization of apo-C38/C81/C96 $\mathrm{R} 1_{4}$, a stock of $700 \mu \mathrm{M}$ tetramer was prepared in $20 \mathrm{mM}$ MOPS, pH 7, with $150 \mathrm{mM} \mathrm{NaCl}$. For crystallization of $\mathrm{Zn}$-C38/C81/C96 R 1 $1_{4}$, a $375 \mu \mathrm{M}$ stock of apo-protein in assembly buffer $(20 \mathrm{mM}$ Tris, pH 7, with $150 \mathrm{mM}$ $\mathrm{NaCl}$ ) was prepared and preincubated with $2250 \mu \mathrm{M} \mathrm{ZnCl}{ }_{2}$. Screens were carried out by sitting-drop vapor diffusion at room temperature with $500 \mu \mathrm{L}$ reservoirs and droplets consisting of $1.5 \mu \mathrm{L}$ of protein and $1 \mu \mathrm{L}$ of precipitant solution. Crystals of metal-free $\mathrm{C} 38 / \mathrm{C} 81 / \mathrm{C} 96 \mathrm{R} 1_{4}$ were obtained with a precipitant solution consisting of $0.1 \mathrm{M}$ Bis-Tris $(\mathrm{pH}$ 6.5) and 45\% 2-methyl-2,4-pentanediol, and crystals of $\mathrm{Zn}$ C38/C81/C96 $\mathrm{R}_{4}$ were obtained with a precipitant consisting of $0.2 \mathrm{M} \mathrm{MgCl}_{2}, 0.1 \mathrm{M}$ Bis-Tris (pH 6.5), and 35\% PEG 400. Crystals were harvested, cryoprotected in perfluoropolyether cryo oil (Hampton Research), and stored in liquid nitrogen. X-ray diffraction data for apo-C38/C81/C96 $\mathrm{R} 1_{4}$ and ZnC38/C81/C96 $\mathrm{R}_{4}$ were collected at $100 \mathrm{~K}$ on beamlines BL9-2 and BL14-1, respectively, at the Stanford Synchrotron Radiation Lightsource. Diffraction data were integrated using Web-Ice. ${ }^{10}$ Integrated datasets were scaled using SCALA ${ }^{11}$ within the CCP4 suite. Molecular replacement was carried out using Phaser ${ }^{12}$ with a C96R1 monomer (PDB ID: 3IQ6) as the search model. Data refinement and model building were carried out using REFMAC ${ }^{13}$ and COOT ${ }^{14}$. Four-fold non-crystallographic symmetry (NCS) restraints were applied in the initial stages of refinement and gradually relaxed. Ramachandran plots were 
calculated using PROCHECK. ${ }^{15}$ All structure figures and structural alignments were generated using PyMOL (www.pymol.org).

2.6 Isothermal titration calorimetry. Experiments were carried out on a VP-ITC instrument (MicroCal) with a cell volume of $1.4125 \mathrm{~mL}$. Samples of C96 R $1_{4}$, C81/C96 R $1_{4}$ and C38/C81/C96 R $1_{4}$ were bufferexchanged into a solution of $20 \mathrm{mM}$ MOPS (pH 7) and $150 \mathrm{mM} \mathrm{NaCl}$ previously treated with Chelex100 Resin (BioRad). Protein samples were then dialyzed twice at $4{ }^{\circ} \mathrm{C}$ for $>8 \mathrm{~h}$ against the indicated buffer, with the second dialysis buffer retained for diluting protein samples and preparing $\mathrm{ZnCl}_{2}$ titrant solutions. The calorimeter cell contained 25-50 $\mu \mathrm{M}$ of apo-tetramer and a water reference. The cell was equilibrated at $22{ }^{\circ} \mathrm{C}$ for $180 \mathrm{~s}$ before an initial injection of $1 \mu \mathrm{L}$ of $1.4 \mathrm{mM} \mathrm{ZnCl}_{2}$ titrant, followed by a schedule of 30 injections of $5.5 \mu \mathrm{L} \mathrm{ZnCl}{ }_{2}$ delivered at 5 min intervals. Data analysis was carried out using the ORIGIN data analysis plugin from MicroCal. The initial injection was omitted from data analysis. Integrated data were background-subtracted using the final injections of the thermogram to account for metal dilution effects, and were fit to a four-site sequential binding model. ITC thermograms were fit using dissociation constants determined by fluorescence competition assays, and enthalpy values were allowed to vary. The dissociation constants could not be directly determined by ITC owing to the tight binding constants (requiring $\sim 40 \mu \mathrm{M}$ protein to measure the weakest binding events, and even lower concentrations for tighter binding) and low enthalpies of binding (requiring $\sim 50 \mu \mathrm{M}$ binding site to achieve $1 \mu \mathrm{cal}$ /injection). Therefore, the reported experimental conditions gave a value of $c>1000$ (where $c$ is the concentration of binding sites divided by the dissociation constant). This limitation has also been reported in other metalloprotein systems with high metal-binding binding affinities, where an ancillary experiment (e.g., equilibrium dialysis) can be used instead to determine the dissociation constants. ${ }^{16}$ As previously noted, ${ }^{16}$ the use of two independent experiments has the added benefit of avoiding correlated errors in determining $\Delta \mathrm{G}$ and $\Delta \mathrm{H}$ from measuring both parameters by ITC. Finally, we note that the complexity of $\mathrm{Zn}^{2+}$ binding to the $\mathrm{R} 1_{4}$ scaffolds (four $\Delta \mathrm{H}_{\mathrm{ITC}}$ 's and four $\mathrm{K}_{\mathrm{d}}$ 's, giving eight free parameters in total) necessitate a complex model that may not robustly measure these binding parameters on a per-site basis. Therefore, we employed an analysis of the global binding parameters supported by additional experiments. Representative raw and integrated thermograms, as well as their best-fit curves, are reported in Figure S5, and the measured $\Delta \mathrm{H}_{\mathrm{ITC}}$ values in Table S1.

\section{References}

(1) Brodin, J. D.; Medina-Morales, A.; Ni, T.; Salgado, E. N.; Ambroggio, X. I.; Tezcan, F. A. F. Am. Chem. Soc. 2010, 132, 8610.

(2) Medina-Morales, A.; Perez, A.; Brodin, J. D.; Tezcan, F. A. F. Am. Chem. Soc. 2013, 135, 12013.

(3) Katz, B. A.; Kossiakoff, A. F. Biol. Chem. 1986, 261, 15480.

(4) Ahmad, S.; Gromiha, M.; Fawareh, H.; Sarai, A. BMC Bioinf. 2004, 5, 51.

(5) Faraone-Mennella, J.; Tezcan, F. A.; Gray, H. B.; Winkler, J. R. Biochemistry 2006, 45, 10504.

(6) Arslan, E.; Schulz, H.; Zufferey, R.; Kunzler, P.; Thony-Meyer, L. 1998, 251, 744.

(7) Schuck, P. Biophys 7 2000, 78, 1606.

(8) Grynkiewicz, G.; Poenie, M.; Tsien, R. Y. J. Biol. Chem. 1985, 260, 3440.

(9) Kuzmic, P. Anal Biochem 1996, 237, 260.

(10) Gonzalez, A.; Moorhead, P.; McPhillips, S. E.; Song, J.; Sharp, K.; Taylor, J. R.; Adams, P. D.; Sauter, N. K.; Soltis, S. M. 7 Appl Crystallogr 2008, 41, 176. 
(11) Winn, M. D.; Ballard, C. C.; Cowtan, K. D.; Dodson, E. J.; Emsley, P.; Evans, P. R.; Keegan, R. M.; Krissinel, E. B.; Leslie, A. G.; McCoy, A.; McNicholas, S. J.; Murshudov, G. N.; Pannu, N. S.; Potterton, E. A.; Powell, H. R.; Read, R. J.; Vagin, A.; Wilson, K. S. 2011, 67, 235.

(12) McGoy, A. J.; Grosse-Kunstleve, R. W.; Adams, P. D.; Winn, M. D.; Storoni, L. C.; Read, R. J. J. Appl. Crystallogr. 2007, 40, 658.

(13) Murshudov, G. N.; Vagin, A. A.; Dodson, E. J. Acta Crystallogr. D Biol. Crystallogr. 1997, 53, 240.

(14) Emsley, P.; Cowtan, K. Acta Crystallogr. D Biol. Crystallogr. 2004, 60, 2126.

(15) Laskowski, R. A.; Macarthur, M. W.; Moss, D. S.; Thornton, J. M. F. Appl. Crystallogr. 1993, $26,283$.

(16) DiTusa, C. A.; Christensen, T.; McCall, K. A.; Fierke, C. A.; Toone, E. J. Biochemistry 2001, 40, 5338. 